\title{
Establishment of a cryopreserved biobank for the Culture Collection of Freshwater Microalgae (CCMA-UFSCar), São Paulo, Brazil
}

\author{
Leticia Piton Tessarolli ${ }^{*}$, John Godfrey Day ${ }^{2}$ \& Armando Augusto Henriques Vieira ${ }^{1}$ \\ ${ }^{1}$ Universidade Federal de São Carlos, Departamento de Botânica, São Carlos, SP, Brazil \\ ${ }^{2}$ Scottish Association for Marine Science, Culture Collection of Algae and Protozoa, Oban, Argyll and Bute, \\ United Kingdom of Great Britain and Northern Ireland \\ *Corresponding author: Leticia Piton Tessarolli, e-mail: letessarolli@gmail.com
}

TESSAROLLI, L.P., DAY, J.G., VIEIRA, A.A.H. Establishment of a cryopreserved biobank for the Culture Collection of Freshwater Microalgae (CCMA-UFSCar), São Paulo, Brazil. Biota Neotropica. 17(2): e20160299, http://dx.doi.org/10.1590/1676-0611-BN-2016-0299

\begin{abstract}
The Culture Collection of Freshwater Microalgae (CCMA-UFSCar, Coleção de Culturas de Microalgas de Água-Doce), based at the Universidade Federal de São Carlos, plays an important role in underpinning Brazilian microalgal research, providing biological materials, substrates and training personnel for a large proportion of the past and current projects in this area. However, recent efforts to expand the culture catalogue/holdings have reached a ceiling because of the logistical practicality of maintaining actively growing cultures. In order to reduce the costs associated with the maintenance regime of cultures, efforts were initiated on the establishment of a cryopreserved biobank for long term maintenance of cultures, thus minimizing the efforts associated with handling of material, as successfully frozen cultures, in theory, could be maintained effectively indefinitely, with the advantage of the stability of cells characteristics. Initial tests were performed on 93 strains including exemplar taxa across the different taxonomic groups in the collection catalogue. The highest levels of success were achieved for the smaller taxa, such as the small green algae; while for the larger and more complex organisms limited to no success was obtained. For the strains tested, over $70 \%$ had positive good levels of post-thaw viability and regenerated phenotypically normal cultures.
\end{abstract}

Keywords: Cryopreservation; freshwater microalgae; biobank

\section{Estabelecimento de um biobanco criopreservado para a Coleção de Culturas de Microalgas de Água-Doce (CCMA-UFSCar), São Paulo, Brasil}

\begin{abstract}
Resumo: A Coleção de Culturas de Microalgas de Água-Doce (CCMA-UFSCar), localizada na Universidade Federal de São Carlos tem um importante papel na sustentação da pesquisa brasileira em microalgas, provendo material biológico, substratos e treinamento de pessoal para uma grande fração dos projetos atuais nessa área. Entretanto, os recentes esforços para expandir o catálogo de culturas atingiram um limite máximo em praticidade logística para a manutenção de culturas metabolicamente ativas. Buscando reduzir os custos do regime de manutenção das culturas, foi-se iniciado o estabelecimento de um banco criopreservado para a manutenção em longo prazo desses organismos, minimizando os gastos com manuseio do material, visto que culturas congeladas com sucesso podem, em teoria, serem mantidas por prazos indeterminados, ainda com a vantagem da estabilidade das características nas culturas. Testes iniciais foram realizados com 93 linhagens, incluindo organismos de diferentes grupos taxonômicos mantidos na coleção de culturas. As maiores taxas de sucesso foram observadas nos organismos menores, como as pequenas algas verdes, enquanto os organismos maiores e mais complexos obtiveram sucesso limitado. Em geral, para as linhagens testadas, acima de $70 \%$ dos organismos apresentaram resposta positiva ao processo.
\end{abstract}

Palavras-chave: criopreservação, microalgas de água-doce, biobancos.

\section{Introduction}

The Culture Collection of Freshwater Microalgae (Coleção de Culturas de Microalgas de Água-doce-CCMA-UFSCar), based at Universidade Federal de São Carlos was the first of its genre to be established in Brazil, in 1977, by Dr. Armando Vieira (Lourenço \& Vieira 2004). It is currently the largest microalgae collection in Brazil, holding around 700 strains of freshwater microalgae, mostly isolated from diverse water bodies in Sao Paulo State, Brazil. This collection has been the source of samples for work undertaken by both public and private institutions, across a wide range of academic and biotechnological projects. Furthermore, it has also been responsible for the specialized training of personnel, including researchers which went to initiate other algae culture collections in Brazil. Recently, renewed efforts were concentrated in the expansion of the collections holdings, as part of the BIOTA-Fapesp network.

Traditionally, strains at CCMA-UFSCar were maintained in replicate as metabolically active cultures under suboptimal growth conditions, which must be sub-cultured every 2-3 months (Vieira, pers. comm) to maintain 
their viability. These cultures are readily available for further application and distribution; however, for their successful maintenance, conditions must be carefully considered and met, such as the culture medium, light, temperature and the intervals between transfers (Lorenz et al. 2005). Also, species may greatly differ in their needs for growth, with specifications and requirements for their successful maintenance (Brand et al. 2013). Thus, the maintenance of metabolically active cultures is a laborious activity which requires a well-designed space and dedicated highly trained personnel. This necessitates significant investment in facilities, personnel and consumables for the upholding of the collection. Also, the sub-culturing process carries several risks for the cultures, mostly related to the transferring activities, as it opens possibilities for cross-contamination of samples, mislabeling, or contaminations from outside organisms, which can lead to the loss of strains when not carefully monitored (Brand et al. 2013; Day \& Brand 2005; Lorenz et al. 2005), or raise the requirements for their maintenance with the need for re-isolation and decontamination over time. Besides the trained personnel to perform these functions associated with the maintenance of metabolically active cultures, a further requirement is a dedicated infrastructure, with controlled temperature and illumination and sufficient space to allow the further expansion of the collection holdings.

In order to reduce the costs of maintenance and the exposure of strains to sources of contamination and deterioration of samples, cryopreservation is recommended for the long term maintenance of samples in an arrested state (OECD 2007). This type of methodology reduces the routine costs for the culture collection, increasing the capacity of expansion of the holdings while insuring the stability and purity of samples and reducing the risks of contamination during the handling of samples. The recent expansion of the CCMA-UFSCar holdings has increased the volume of work associated with the maintenance of active cultures, which is rapidly reaching unsustainable levels under the current regime in the terms of investment and resource requirements. Furthermore, recently, contamination events by fungus and other organisms have occurred, which in turn increased the workload associate with the collections curation. Therefore, efforts were raised and focused on the establishment of a cryopreserved biobank for the culture collection, in order to secure the collection holdings, which are the focus of much of the research work of the laboratory and source of samples for many research groups in Brazil.

\section{Material and Methods}

\section{Establishment of the cryobank infrastructure}

The CCMA-UFSCar has been established as a culture collection for almost 40 years at its current location, maintaining metabolically active cultures. It is registered at the World database for Culture Collections with the reference WDCM 835. However, cryopreservation efforts were only recently initiated. Thus, adjustments of the laboratory infrastructure were necessary to facilitate the successful implementation of cryopreservation protocols for the maintenance of existing and recently incorporated microalgae strains from the culture collection. The acquisition of the necessary equipment was funded by the FAPESP Thematic Project (2011/50054-4), and included: a controlled rate freezer (CRF) Planer Kryo 3601.7 (Planer PLC, UK) with associated software which allows the control of the cryopreservation process; an Ultra-Low temperature freezer (Revco Value Series, Thermo Scientific, USA); sample storage dewar SC-47 R (Sempercrio, Brazil) and nitrogen transportation dewar SC-60/I (Sempercrio, Brazil).

\section{Training on cryopreservation techniques}

As part of the initial activities of the project, the training on the required techniques was undertaken at the Culture Collection of Algae and Protozoa (CCAP), based at the Scottish Association for Marine Science (SAMS),
Oban, UK. The CCAP has over 40 year's expertise on the maintenance of frozen strains of marine and freshwater algae and protozoa. The training included basic theory and practical protocols for the successful maintenance of strains at ultra-low temperatures, which were further adapted for applicability using the Brazilian laboratory facilities. These experiences were applied for the development of the standard operating procedure (SoP) for cryopreservation of freshwater strains at CCMA-UFSCar.

\section{Collection Holdings}

CCMA-UFSCar currently holds almost 700 strains of freshwater microalgae, from a wide range of groups. From these, 133 strains are currently maintained in axenic cultures, which are periodically checked for bacterial proliferation using WC medium (Guillard \& Lorenzen 1972) modified by the addition of glucose and peptone ( $250 \mathrm{mg} . \mathrm{L}^{-1}$ each), in a visual analysis. The remaining cultures of the collection are maintained as uni-algal cultures after isolation from environmental samples.

For the initial establishment of the cryopreserved biobank, efforts were focused on the maintenance of the axenic strains, which are currently the main focus of further research at the Phycology Laboratory at UFSCar. The tests included 93 strains of freshwater microalgae, mostly Chlorophyceae (62 strains), but also including organisms from Conjugatophyceae (11 strains), Trebouxiophyceae (7 strains), Cryptophyceae (1 strain), Synurophyceae (1 strain), Xantophyceae (2 strains) and Bacillariophyceae (9 strains). The effects of the presence of a contaminant heterotrophic community within the microalgae cultures on the viability and recovery of post-thaw cultures were also analyzed using 18 strains of non-axenic microalgae.

\section{Freezing Protocol}

Initially, a commonly employed protocol was applied for all the tested organisms, to establish the main database for the maintenance of cryopreserved organisms at CCMA-UFSCar. For this, a cryoprotectant solution/Cryoprotective Additive (CPA) of dimethyl sulfoxide (DMSO) was prepared in the appropriate culture medium at $10 \%$ concentration $(\mathrm{v} / \mathrm{v})$. All strains of microalgae were cryopreserved using a two-step, controlled rate cooling protocol as previously described by Day \& Brand (2005). Briefly, an aliquot of $0.5 \mathrm{~mL} 10 \%(\mathrm{v} / \mathrm{v})$ cryoprotectant solution was added to $0.5 \mathrm{~mL}$ of a dense microalgal culture in a cryovial, which was incubated for $15 \mathrm{~min}$ at room temperature, out of direct light to ensure the cryoprotectant action. Samples were then transferred to a controlled rate cooler (Planer, UK) at a start temperature of $20^{\circ} \mathrm{C}$. Cultures were then cooled at a cooling rate of $-1^{\circ} \mathrm{C} \cdot \mathrm{min}^{-1}$ to $-40{ }^{\circ} \mathrm{C}$, held at this temperature for $15 \mathrm{~min}$ and then plunged into liquid nitrogen. Samples were transferred to the local cryostorage facility and three samples of each cryopreserved strain were thawed for viability analysis. Where this conventional approach proved unsuccessful a series of empirical studies were performed to optimize the applicability of the approach to the broader holdings of CCMA-UFSCar (Figure 1).

\section{Toxicity of the CPA solutions}

Simultaneously to testing the standard freezing protocols, the toxicity of DMSO 5\% (final concentration during cryopreservation) was assessed for several strains of microalgae. This test consisted in the mixture equal parts of CPA solution (10\%) and microalgae culture, which were incubated for $15 \mathrm{~min}$ at room temperature. Aliquots $(1 \mathrm{~mL})$ of the samples were then diluted in $10 \mathrm{~mL}$ of fresh medium, and maintained to the standard culturing/ incubation conditions of the bank: $100 \mu \mathrm{mol} \mathrm{m} \mathrm{m}^{-2} \mathrm{~s}^{-1}$ (photosynthetically active radiation), with a $12: 12 \mathrm{~h}$ dark:light cycle and at a temperature of $23 \pm 1^{\circ} \mathrm{C}$ for growth. The viability of these samples was determined analyzing culture growth after 2-3 weeks of incubation under the above regime, using Chl-a fluorescence (see 8). 


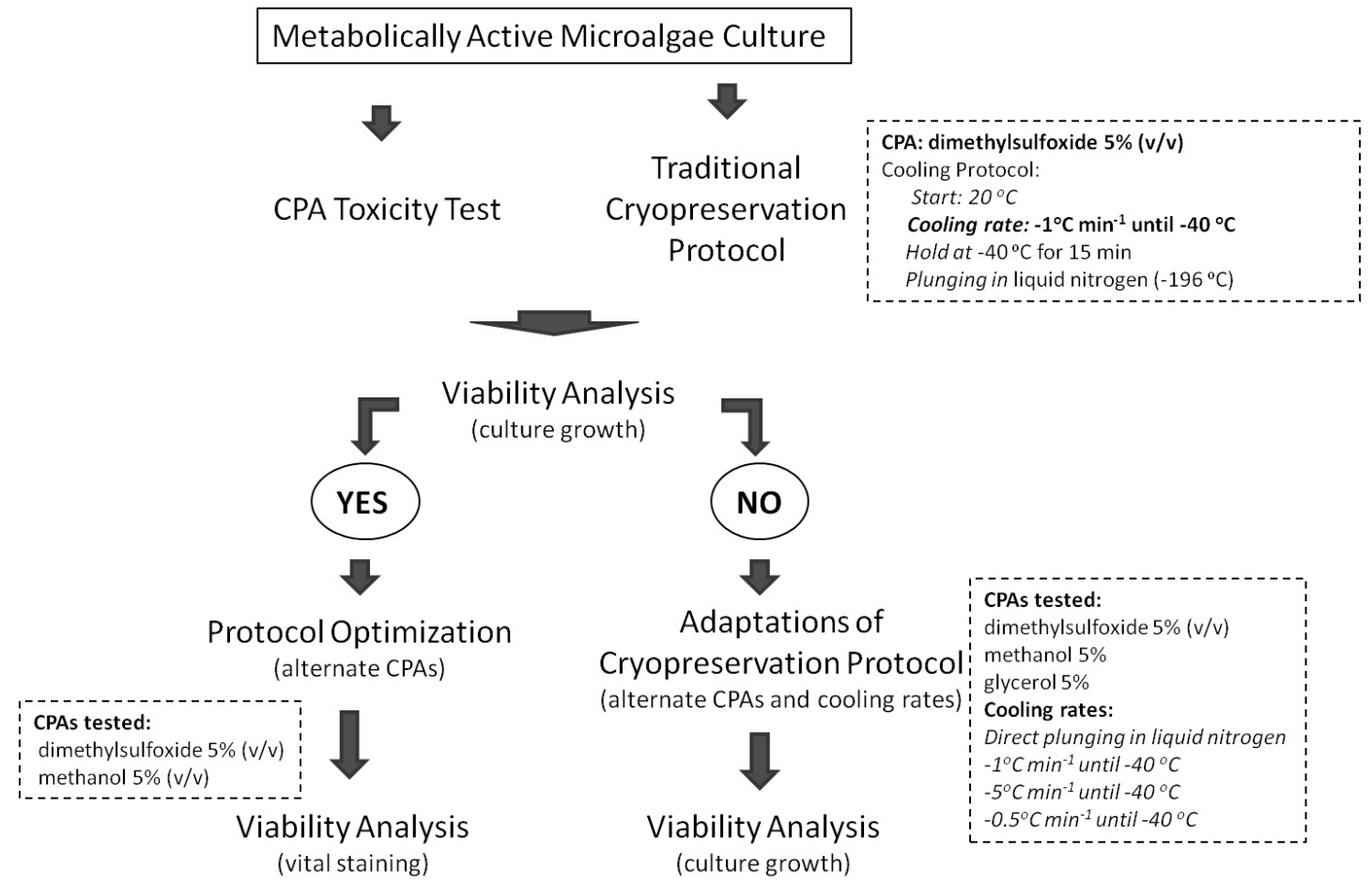

Figure 1. Flowchart of empirical development of effective cryopreservation protocols.

\section{Alternate freezing protocols: analyzing the success rates of dimethylsulfoxide (DMSO) and methanol (MeOH) for the cryoprotection of axenic and non-axenic samples.}

The possibility of employing $\mathrm{MeOH}$ as an alternative to DMSO for the cryopreservation of 18 strains of microalgae was verified. In this test, the cooling protocol previously described was employed, exchanging the CPA solution from DMSO 10\% for a methanol 10\% solution, prepared under the same conditions. For this study, viability measurements were performed using vital staining, with erythrosine-b (see 8).

\section{Cryopreservation of Chlamydomonas chlorastera: assessment of different cooling rates and cryoprotectant agents.}

The initial attempt to cryopreserve Chlamydomonas chlorastera (CCMA-UFSCar 009) with the previously described two-step protocol using DMSO 5\% as CPA was unsuccessful, with no recovery of viable algae from the samples. Thus, several adaptations on the cooling rates and CPA employed for cell protection during the process were tested in order to obtain the most successful protocol for the maintenance of this species in liquid nitrogen for long term storage. Combinations of three different CPAs (methanol, DMSO and Glycerol) and four different cooling rates were tested for cryopreservation of a $C$. chlorastera culture while in exponential growth phase, generating 20 different freezing treatments. The toxicity of the CPA in the samples was also assessed by the exposure of samples to higher concentrations of these compounds, with subsequent dilution to "innocuous" concentrations. The viability of samples was assessed using the absorbance of samples after recovery and monitoring of subsequent growth.

\section{Thawing of samples and viability analysis}

The stored cryovials were transferred from the cryostore to a small Dewar containing liquid nitrogen. These were thawed in a pre-heated water bath $\left(40^{\circ} \mathrm{C}\right)$ until all visible ice had melted (Day \& Stacey 2007). They were then rapidly transferred to a laminar flow cabinet, the outside of the cryovial wiped with $70 \%(\mathrm{v} / \mathrm{v})$ ethanol, to reduce the risk of contamination by adhering bacteria, caps aseptically removed and using a sterile pipette, the contents $(0.5 \mathrm{ml})$ from each of the three thawed replicate samples were transferred into culture tubes with $10 \mathrm{~mL}$ of $\mathrm{WC}$ medium to dilute the potentially toxic characteristics of the cryoprotectant. Cultures were maintained for 24-36h in the dark and then incubated under the standard culturing conditions of the bank: $100 \mu \mathrm{mol} \mathrm{m}^{-2} \mathrm{~s}^{-1}$ (photosynthetically active radiation), with a $12: 12 \mathrm{~h}$ dark:light cycle and at a temperature of $23 \pm 1^{\circ} \mathrm{C}$. Assessment of viability was performed after 2- 3 weeks of incubation under the above cultivation regime, with analysis of the Chl-a fluorescence using a Trilogy Laboratory Fluoremeter (Turner Designs, USA) equipped with a chlorophyll in vivo Module (7200-043).

Alternatively, for the comparison of the efficacy of using DSMO or $\mathrm{MeOH}$ as CPA, the viability of samples was assessed using microscopy analysis of samples stained with erythrosine-b (SIGMA). This stain can only permeate dead cells, which will acquire the red color, while the living (viable) cells maintain their natural green color. The viability of samples before cryopreservation was assessed for control and standardization of results. After cryopreservation, $100 \mu \mathrm{L}$ of the culture were separated in a $200 \mu \mathrm{L}$ PCR tube, to which $30 \mu \mathrm{L}$ of a saturated erythrosine solution was added and mixed. After $15 \mathrm{~min}$, samples were analyzed by optical microscopy and the number of cells stained (red) and not stained (green) annotated, (a minimum of 50 cells were counted on each slide). The viability of the samples was calculated dividing the number of living cells (green) by the total amount of cells counted (red+green), multiplying the results by 100 to obtain the percentage. In order to avoid the sub estimation of viability due to the presence of dead cells in the original cultures (prior to freezing), the viability of these samples was also calculated and considered for the final viability results. When applicable, comparisons between treatments with the different CPAs were performed using t-tests to determine the species in which significant differences of viability were observed. 


\section{Results}

\section{Traditional cryopreservation protocol}

The applicability of the conventional two-step protocol tested in this project generated a range of results, considering the wide range of groups in the 93 strains analyzed. The distribution of these results has been summarized in Figure 2. The group with the highest success rates i.e. highest levels of recovery after freezing was the Chlorophyceae, with 58 strains successfully cryopreserved (92\%). The application of the standard method to the Conjugatophyceae and diatoms was the least successful, with success in $9 \%$ and $22 \%$ of the strains tested, respectively.

For the Chlorophyceae, the family Selenastraceae was the most intensively studied group, with 44 strains (Table 1). Most species of this group successfully recovered after cryopreservation; however, a few exceptions were observed in strains of Selenastrum bibraianum and two strains of Kirchneriella. Similar results were observed for the family Scenedesmaceae, where comparably high viability levels after application of the standard cryopreservation protocol were observed, with all the samples tested able to regenerate robust cultures on transfer to fresh medium (Table 2).

Table 1. Viability of samples from the family Selenastraceae (Chlorophyceae) after recovery from cryopreservation protocol.

\begin{tabular}{|c|c|c|c|c|c|}
\hline \multicolumn{2}{|c|}{ Accession number } & Strain & CPA & r ABS (\%) & \\
\hline CCMA-UFSCar & 003 & Ankistrodesmus densus & DMSO $5 \%$ & 81 & $\sqrt{ }$ \\
\hline CCMA-UFSCar & 005 & Messastrum gracile & DMSO 5\% & 89 & $\checkmark$ \\
\hline CCMA-UFSCar & 024 & Monoraphidium arcuatum & DMSO $5 \%$ & 95 & $\checkmark$ \\
\hline CCMA-UFSCar & 047 & Selenastrum bibraianum & DMSO 5\% & 52 & $\checkmark$ \\
\hline CCMA-UFSCar & 048 & Raphidocelis subcapitata & DMSO $5 \%$ & 47 & $\checkmark$ \\
\hline CCMA-UFSCar & 063 & Selenastrum bibraianum & DMSO 5\% & 7 & $x$ \\
\hline CCMA-UFSCar & 083 & Ankistrodesmus flexuosus & DMSO 5\% & 73 & $\sqrt{ }$ \\
\hline CCMA-UFSCar & 123 & Kirchneriella aperta & DMSO $5 \%$ & 33 & $\checkmark$ \\
\hline CCMA-UFSCar & 125 & Selenastrum bibraianum & DMSO 5\% & 55 & $\checkmark$ \\
\hline CCMA-UFSCar & 128 & Ankistrodesmus densus & DMSO $5 \%$ & 100 & $\checkmark$ \\
\hline CCMA-UFSCar & 137 & Chlorolobion cf. braunii & DMSO 5\% & 89 & $\checkmark$ \\
\hline CCMA-UFSCar & 168 & Selenastrum bibraianum & DMSO 5\% & 76 & $\sqrt{ }$ \\
\hline CCMA-UFSCar & 174 & Kirchneriella irregularis var. spiralis & DMSO 5\% & 85 & $\checkmark$ \\
\hline CCMA-UFSCar & 176 & Monoraphidium griffithii & DMSO 5\% & 100 & $\checkmark$ \\
\hline CCMA-UFSCar & 230 & Kirchneriella irregularis & DMSO $5 \%$ & 84 & $\checkmark$ \\
\hline CCMA-UFSCar & 234 & Kirchneriella irregularis var. spiralis & DMSO $5 \%$ & 100 & $\sqrt{ }$ \\
\hline CCMA-UFSCar & 239 & Ankistrodesmus densus & DMSO $5 \%$ & 100 & $\checkmark$ \\
\hline CCMA-UFSCar & 241 & Selenastrum bibraianum & DMSO 5\% & 62 & $\checkmark$ \\
\hline CCMA-UFSCar & 278 & Ankistrodesmus stipitatus & DMSO 5\% & 95 & $\sqrt{ }$ \\
\hline CCMA-UFSCar & 306 & Monoraphidium contortum & DMSO $5 \%$ & 100 & $\checkmark$ \\
\hline CCMA-UFSCar & 325 & Monoraphidium pseudobraunii & DMSO 5\% & 61 & $\checkmark$ \\
\hline CCMA-UFSCar & 333 & Monoraphidium kormakovae & DMSO $5 \%$ & 100 & $\checkmark$ \\
\hline CCMA-UFSCar & 345 & Kirchneriella obesa & DMSO 5\% & 75 & $\checkmark$ \\
\hline CCMA-UFSCar & 346 & Kirchneriella pseudoaperta & DMSO $5 \%$ & 63 & $\checkmark$ \\
\hline CCMA-UFSCar & 348 & Kirchneriella irregularis & DMSO 5\% & 94 & $\checkmark$ \\
\hline CCMA-UFSCar & 349 & Monoraphidium contortum & DMSO $5 \%$ & 100 & $\checkmark$ \\
\hline CCMA-UFSCar & 350 & Curvastrum pantanale & DMSO $5 \%$ & 92 & $\checkmark$ \\
\hline CCMA-UFSCar & 353 & Monoraphidium kormakovae & DMSO 5\% & 90 & $\checkmark$ \\
\hline CCMA-UFSCar & 423 & Ankistrodesmus bernardii & DMSO 5\% & 82 & $\checkmark$ \\
\hline CCMA-UFSCar & 447 & Kirchneriella contorta var. elegans & DMSO 5\% & 74 & $\checkmark$ \\
\hline CCMA-UFSCar & 455 & Chlorolobion braunii & DMSO 5\% & 100 & $\checkmark$ \\
\hline CCMA-UFSCar & 462 & Chlorolobion braunii & DMSO 5\% & 92 & $\checkmark$ \\
\hline CCMA-UFSCar & 470 & Messastrum gracile & DMSO $5 \%$ & 94 & $\checkmark$ \\
\hline CCMA-UFSCar & 476 & Chlorolobion braunii & DMSO 5\% & 100 & $\checkmark$ \\
\hline CCMA-UFSCar & 478 & Raphidocelis subcaptata & DMSO $5 \%$ & 89 & $\checkmark$ \\
\hline CCMA-UFSCar & 492 & Pseudokirchneriella elongata & DMSO 5\% & 100 & $\checkmark$ \\
\hline CCMA-UFSCar & 498 & Pseudokirchneriella elongata & DMSO 5\% & 81 & $\checkmark$ \\
\hline CCMA-UFSCar & 516 & Kirchneriella obesa & DMSO 5\% & 93 & $\sqrt{ }$ \\
\hline CCMA-UFSCar & 549 & Monoraphidium indicum & DMSO 5\% & 100 & $\checkmark$ \\
\hline CCMA-UFSCar & 604 & Chlorolobion lunatum & DMSO $5 \%$ & 100 & $\checkmark$ \\
\hline CCMA-UFSCar & 606 & Monoraphidium irregularis & DMSO 5\% & 79 & $\checkmark$ \\
\hline CCMA-UFSCar & 609 & Desmodesmus comunis & DMSO 5\% & 96 & $\checkmark$ \\
\hline CCMA-UFSCar & 611 & Ankistrodesmus fusiformis & DMSO 5\% & 93 & $\checkmark$ \\
\hline CCMA-UFSCar & 622 & Messastrum gracile & DMSO $5 \%$ & 100 & $\sqrt{ }$ \\
\hline
\end{tabular}

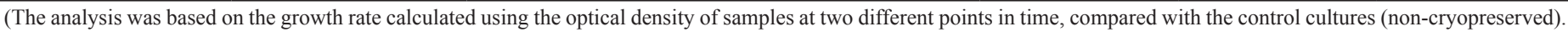
The symbols and colors indicate the relative success of growth: green - good growth, yellow - medium success and red - poor growth.) 
Cryopreserved biobank at CCMA-UFSCar

Table 2. Viability of samples from the family Scenedesmaceae (Chlorophyceae) after recovery from cryopreservation protocol.

\begin{tabular}{|c|c|c|c|c|c|}
\hline \multicolumn{2}{|c|}{ Accession number } & Strain & CPA & r ABS (\%) & \\
\hline CCMA-UFSCar & 029 & Scenedesmus bijugus & DMSO 5\% & 80 & $\checkmark$ \\
\hline CCMA-UFSCar & 030 & Desmodesmus comunis & DMSO $5 \%$ & 86 & $\checkmark$ \\
\hline CCMA-UFSCar & 046 & Desmodesmus spinosus & DMSO 5\% & 75 & $\checkmark$ \\
\hline CCMA-UFSCar & 060 & Coelastrum sphaericum & DMSO $5 \%$ & 78 & $\checkmark$ \\
\hline CCMA-UFSCar & 062 & Desmodesmus spinosus & DMSO $5 \%$ & 88 & $\checkmark$ \\
\hline CCMA-UFSCar & 088 & Scenedesmus ecornis & DMSO 5\% & 82 & $\checkmark$ \\
\hline CCMA-UFSCar & 244 & Verrucodesmus verrucosus & DMSO 5\% & 79 & $\checkmark$ \\
\hline CCMA-UFSCar & 326 & Hariotina reticulata & DMSO $5 \%$ & 100 & $\sqrt{ }$ \\
\hline CCMA-UFSCar & 493 & Hariotina reticulata & DMSO $5 \%$ & 81 & $\checkmark$ \\
\hline CCMA-UFSCar & 609 & Desmodesmus comunis & DMSO $5 \%$ & 96 & $\checkmark$ \\
\hline
\end{tabular}

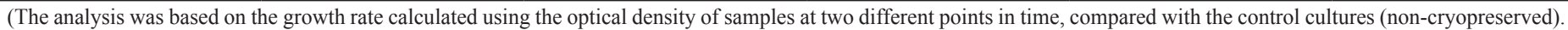
The symbols indicate the relative success of growth: $\checkmark$ - good growth, $X$ - poor growth.)

The bigger and more complex organisms had lower rates of survival, with only one of the desmid strains (Conjugatophyceae) tested demonstrating successful regrowth after the cryopreservation protocol was completed: Spondylosium pygmaeum (CCMA-UFSCar 014). The remaining 10 strains of this group tested had no detectable viability, i.e. they were not able to form new cultures (Figure 2). The experiments with diatoms also had limited success, with only 2 of the 9 strains tested able to regrow after undergoing the cryopreservation protocol (Figure 2).

\section{Toxicity and cryopreservation effects of CPA on axenic strains}

The potential toxicity of DMSO at 5\% as a CPA was not a determinant factor for the cryopreservation of most microalgae strains tested. Measurements of Chl-a fluorescence of samples after 2-3 weeks of growth showed similar patterns for samples with and without treatment with DMSO for $15 \mathrm{~min}$, before dilution in fresh medium (Figure 3).

Cryopreservation using DMSO or $\mathrm{MeOH}$ as CPA had similar results for the majority of the strains tested (15 strains) (Figure 4A). However, for $K$. obesa, K. lunaris and P. duplex, cryopreservation with methanol resulted in slightly better levels of success, although materials subjected to both treatments were able to form new robust cultures after 2 weeks growth.

\section{Post-thaw viability: non-axenic cultures}

Post-thaw viability levels observed for non-axenic cultures were, in general, high and similar to the responses reported for axenic cultures of the same strain frozen employing the same protocol (Figure 4A). Comparisons for the viability of non-axenic strains frozen with $\mathrm{MeOH}$ and DMSO as CPA are detailed in Figure 4B. It was noted that for a few strains, mostly of Kirchneriella spp., significantly $(\mathrm{p}<0.05)$ higher viability was observed with samples treated with $\mathrm{MeOH}$ for cryopreservation.

\section{Cryopreservation of Chlamydomonas chlorastera}

For the study on cryopreservation of Chlamydomonas chlorastera a total of 20 different combinations of CPA and cooling rates were tested for cryopreservation of an actively growing culture (vegetative cells). The objective was to maximize viability levels, as demonstrated by the ability to re-grow robust cultures that were comparable to control cultures (i.e. not frozen sample(s)). $\mathrm{MeOH}$ was found to be an effective CPA, capable of protecting the cells from the freezing damage (Table 3). However, the use of DMSO or Glycerol as CPAs was not effective for the protection of cultures during the process and no re-establishment of cultures was observed for these samples. It was noted that, cultures that were exposed to the CPA for a short period of time before dilution and subsequent incubation under standard conditions showed no inhibitory effects that could be attributed to these compounds at the concentrations tested. This led to the conclusion

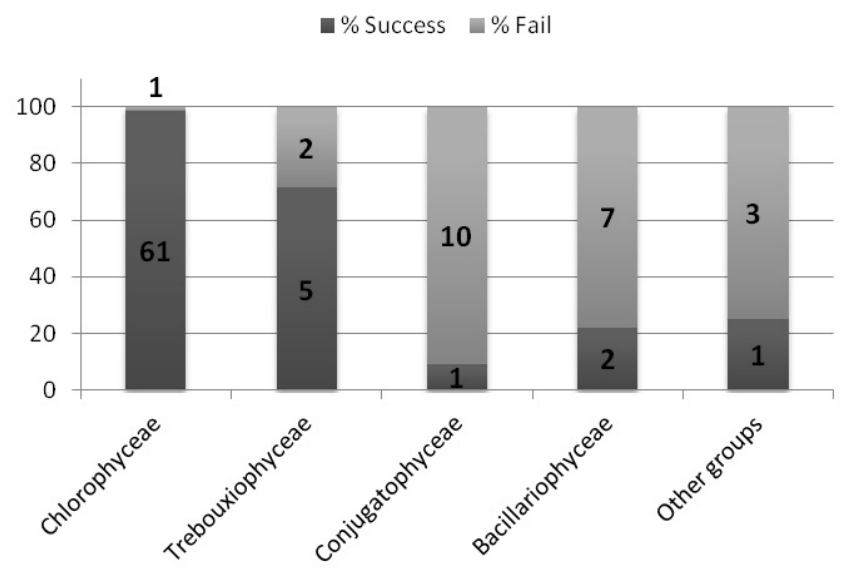

Figure 2. Success and failure percentages for the cryopreservation protocol applied for different groups of freshwater microalgae. The numbers inside the bars are the number of strains tested in each taxonomic group.

Table 3 - Viability of samples Chlamydomonas chlorastera (CCMA-UFSCar 009) after recovery from different cryopreservation protocols, using DMSO, $\mathrm{MeOH}$ or Glycerol as CPA and frozen at three different cooling rates.

\begin{tabular}{|c|c|c|c|}
\hline Treatment & CPA & Cooling rate & \\
\hline T01 & no & not frozen & $\checkmark$ \\
\hline T02 & no & $\mathrm{LN}$ & $x$ \\
\hline T03 & no & $-1^{\circ} \mathrm{C} \min ^{-1}$ & $x$ \\
\hline T04 & no & $-5^{\circ} \mathrm{C} \min ^{-1}$ & $x$ \\
\hline T05 & no & $-0,5^{\circ} \mathrm{C} \mathrm{min}^{-1}$ & $x$ \\
\hline T06 & DMSO 5\% & not frozen & $\checkmark$ \\
\hline T07 & DMSO 5\% & $\mathrm{LN}$ & $x$ \\
\hline T08 & DMSO 5\% & $-1^{\circ} \mathrm{C} \min ^{-1}$ & $x$ \\
\hline T09 & DMSO $5 \%$ & $-5^{\circ} \mathrm{C} \min ^{-1}$ & $x$ \\
\hline $\mathrm{T} 10$ & DMSO 5\% & $-0,5^{\circ} \mathrm{C} \min ^{-1}$ & $x$ \\
\hline $\mathrm{T} 11$ & $\mathrm{MeOH} 5 \%$ & not frozen & $\checkmark$ \\
\hline $\mathrm{T} 12$ & $\mathrm{MeOH} \mathrm{5 \%}$ & $\mathrm{LN}$ & $x$ \\
\hline $\mathrm{T} 13$ & MeOH 5\% & $-1^{\circ} \mathrm{C} \min ^{-1}$ & $\checkmark$ \\
\hline $\mathrm{T} 14$ & MeOH 5\% & $-5^{\circ} \mathrm{C} \min ^{-1}$ & $\checkmark$ \\
\hline $\mathrm{T} 15$ & MeOH 5\% & $-0,5^{\circ} \mathrm{C} \min ^{-1}$ & $\sqrt{ }$ \\
\hline $\mathrm{T} 16$ & Glycerol 5\% & not frozen & $\checkmark$ \\
\hline T17 & Glycerol 5\% & $\mathrm{LN}$ & $x$ \\
\hline T18 & Glycerol 5\% & $-1^{\circ} \mathrm{C} \min ^{-1}$ & $x$ \\
\hline T19 & Glycerol 5\% & $-5^{\circ} \mathrm{C} \min ^{-1}$ & $x$ \\
\hline $\mathrm{T} 20$ & Glycerol 5\% & $-0,5^{\circ} \mathrm{C} \mathrm{min}^{-1}$ & $x$ \\
\hline
\end{tabular}

(The symbols indicate the relative success of growth after visual analysis: $\checkmark$-good growth and $X$ - no growth.) 


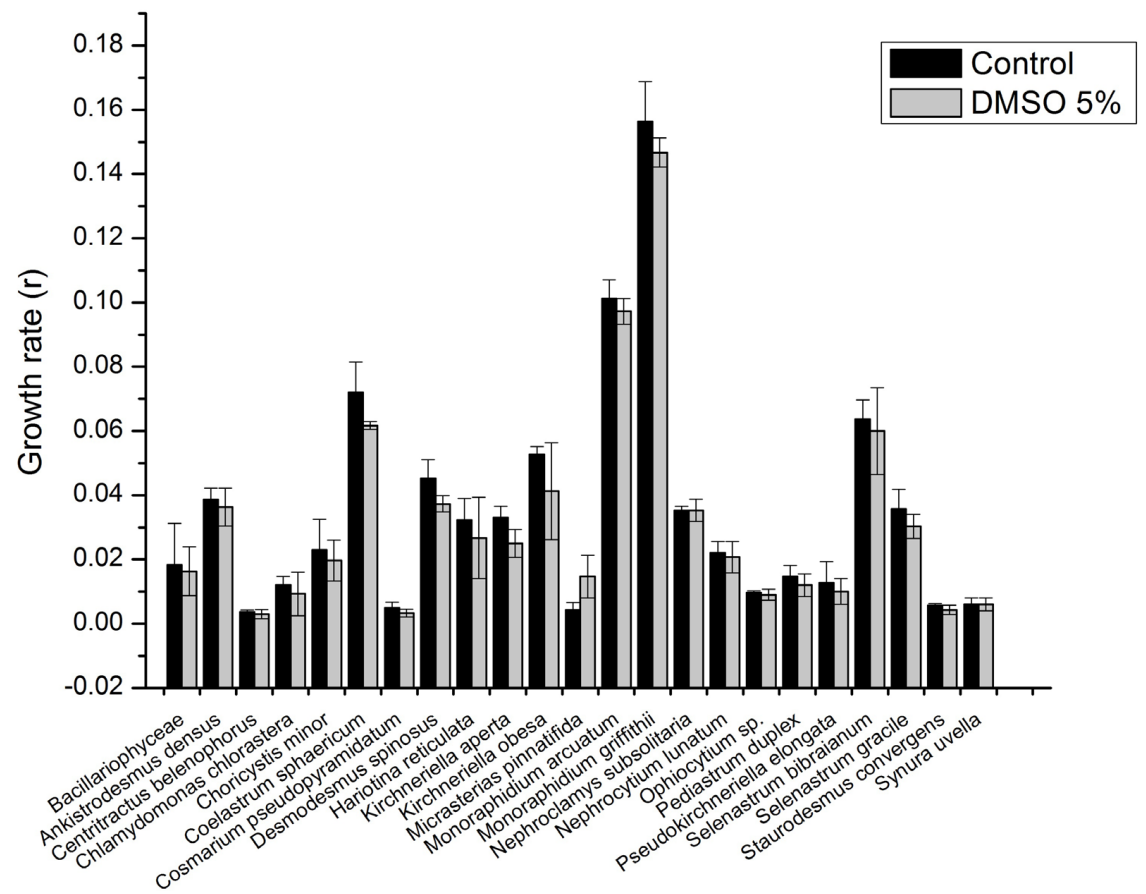

Figure 3. Comparison of growth (Chl-a fluorescence) between samples untreated (Control) and treated (DMSO 5\%) with CPA and incubated for 15 min before dilution in fresh medium. The cultures were grown for 2-3 weeks.

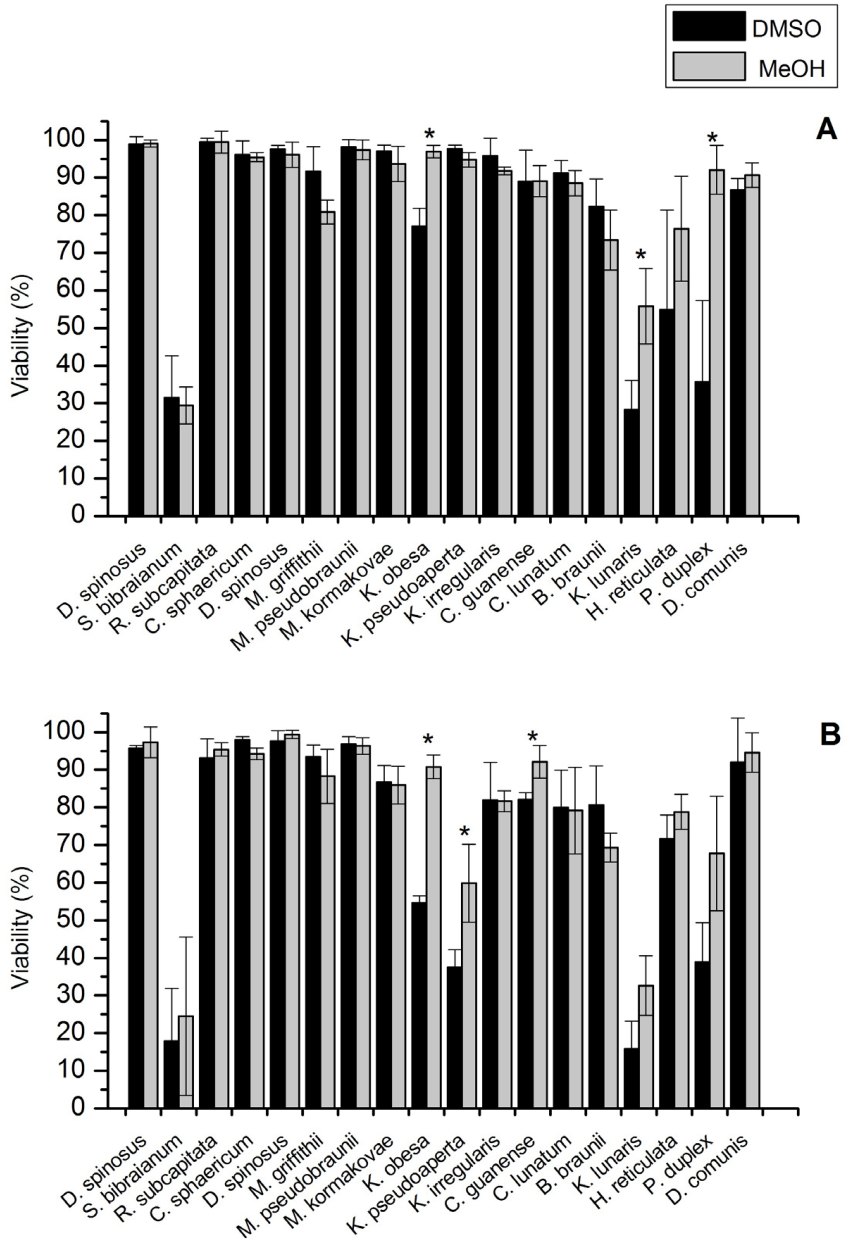

Figure 4. Viability (\%) of samples cryopreserved using different CPAs (DMSO and MeOH) for protection of the cultures. A-axenic cultures and B - non-axenic cultures. * = statistically significant differences in recovery after cryopreservation with $\mathrm{MeOH}$ or DMSO $(\mathrm{p}<0.05)$. 
that the damage happened during the freezing/thawing of cultures and that these compounds had little or no colligative cryoprotective effect for this alga under the cooling regime employed.

\section{Discussion}

\section{CPA: toxicity \& protective effect}

The cryopreservation process results in a range of complex physical, biophysical and chemical changes in both the cells being cryopreserved and their immediate environment, thus careful consideration is required in order to achieve the highest post-thaw viability for samples (Day \& Fleck 2015). One critical point for the success of the process is the addition of a cryoprotective additive (CPA), which is almost always necessary for organisms to survive the lethal consequences of the freezing/thawing process (Doebbler 1966). Penetrative CPAs, such as $\mathrm{MeOH}$ and DMSO can rapidly permeate cell membranes, which in addition to their colligative capabilities of keeping salts in solution, affect the ice crystal nucleation by forming strong hydrogen bonds with water molecules (Weng et al. 2011; Yu \& Quinn 1994). However, altering the solute composition and concentration might have extremely toxic effects, inhibiting the growth of cultures (Hubalek 2003; Yu \& Quinn 1994).

The basic two-step cryopreservation protocol tested for the CCMA-UFSCar microalgae required the exposure of cultures for a minimum 15 min to DMSO 5\% concentrations. As observed for the growth of cultures treated with CPAs (CPA control cultures), for most samples no inhibitory effects were observed from this step and cultures maintained their culture formation ability. Indeed, this approach adheres to this recommended use of DMSO concentrations lower than $15 \%$ to avoid the effects on microalgae cultures, and to carefully consider the temperature of reaction and time of exposure (Hubalek 2003).

\section{Cryopreservation of Chlorophyceae}

Over 50\% of the CCMA-UFSCar biobank holdings are composed of strains belonging to the Phylum Chlorophyta, of which almost $80 \%$ are Chlorophyceae strains, which can be further divided into divided in 20 families. These organisms are the focus of the most recent publications from the research group (Garcia et al. 2017; de Moraes \& Vieira 2014; Vieira et al. 2016), more specifically taxa belonging to the order Sphaeropleales and its families Selenastraceae and Scenedesmaceae. These groups are composed mostly of small organisms, which can be unicellular, or in many cases form small colonies, and thus present a wide range of phenotypic forms (Garcia et al. 2017). Successful cryopreservation of organisms from these groups was verified employing the classic cryopreservation protocol in this study.

Organisms with reduced size and morphological simplicity are generally expected to be the most tolerant to the cryopreservation process (Day \& Brand 2005). The success of the freezing/thawing process is entirely dependent on the equilibrium of water loss by cells, during the cooling process to avoid the formation of intracellular ice, while maintain the necessary conditions for the survival of cells (Day \& Fleck 2015; Mazur 1984). The morphological simplicity of these organisms, coupled with their cell wall characteristics help to maintain viability during the process. This was reflected by the high viability levels observed after the freezing, thawing and recovery cycle.

However it was observed that some strains of Selenastrum bibraianum had more limited levels of recovery (Table 1) from the process. This demonstrated that even organisms very closely related may have specific requirements to ensure the complete success of the protocol (Brand et al. 2013). This was also the case observed for some strains of Kirchneriella, specifically $K$. aperta and $K$. pseudoaperta, where somewhat limited success was observed on application of the standard two-step cryopreservation protocol using DMSO as CPA. Kirchneriella pseudoaperta (CCMA-UFSCar 346) when further tested demonstrated that the ability to form new cultures was maintained; however, the lag phase of the growth curve was a few days longer (data not shown). Furthermore, a change in the protocol, i.e. employing $\mathrm{MeOH}$ as $\mathrm{CPA}$ during the two-step cryopreservation protocol, resulted in slightly better recovery of viability (Figure 4). Once again demonstrating the specific requirements which must be met for each culture to be cryopreserved. However, for most strains tested, no significant $(\mathrm{p}>0.05)$ differences were found in the protection provided by the CPAs tested (Figure 3), which can make them interchangeable for these organisms, giving priority to other aspects to be considered for the long term maintenance of frozen microalgae.

The post-thaw viability levels obtained for the non-axenic strains tested were generally high (Figure 4B) and directly comparable to their axenic counterparts. For Kirchneriella obesa, K. pseudoaperta and C. guanense, viability was higher for samples cryopreserved using $\mathrm{MeOH}$ as CPA $(p<0.05)$, rather than DMSO. The process of cryopreservation of non-axenic strains, beyond the viability of samples assessed immediately after the freezing/thawing cycle, must consider the ability of samples to recover and overcome competition with co-culture organisms. The propagation of the heterotrophic associated community, thus, may lead to inhibition of microalgae growth (Day \& Harding 2008). The choice of CPA, although with limited effect on the viability of samples post-thaw, had direct effect on the recovery of robust cultures of microalgae of non-axenic strains. The utilization of $\mathrm{MeOH}$ as cryoprotectant during this process might be problematic, as although it results in higher viability rates as demonstrated for some strains of Kirchneriella (Figure 4B), it also favors the proliferation of bacteria, verified by the opacity developed in the medium (data not shown), which could inhibit the development of the microalgal culture (Amaral et al. 2013).

\section{Cryopreservation of desmids (Conjugatophyceae) and diatoms (Bacillariophyceae)}

The organisms belonging to the Classes Conjugatophyceae (desmids) and Bacillariophyceae (diatoms) were some of the most recalcitrant groups for the protocols tested, with over $75 \%$ of the strains showing no post-thaw viability of samples. These groups have already been described as problematic for the maintenance in liquid nitrogen, with very few positive results for post-thaw viability (Day 2007). Algae with larger cell sizes and most filamentous algae still cannot be cryopreserved yet, and the higher rates of success were found for smaller, morphologically non-complex algae (Day \& Brand 2005).

Successful cryopreservation protocols are known to reduce osmotic stress, cold shock and potential damage by ice formation, highlighting the importance of the cooling regime (Day et al. 2000) and must be usually empirically determined for the more sensitive strains (Taylor \& Fletcher 1998). In a study with two strains of Micrasterias, Morris et al. (1986) reported that the cell walls did not contract to accompany the shrinkage of the protoplast, which led to the plasmolysis. This was not observed in similar studies with Cylindrocystis brebissonii, emphasizing the importance of cell volume and surface area, cell wall composition, as well as interactions between the wall and cell membrane, and their influence on the cryopreservation process (Morris et al. 1986).

\section{Cryopreservation of Chlamydomonas chlorastera: a protocol study}

The initial negative results for cryopreservation of Chlamydomonas chlorastera (CCMA-UFSCar 009) using DMSO as CPA in a two-step protocol indicated that further research was necessary for the successful long term maintenance of this strain. Thus, tests were performed using 
$\mathrm{MeOH} 5 \%$ and Glycerol 5\%, as well as different cooling rates in order to obtain the highest viability results for these organisms. Although the cooling rates tested were not relevant for this algae, with the exception of the direct plunging of samples in liquid nitrogen, which was lethal independently of CPA, differences were found between CPAs, with $\mathrm{MeOH}$ being the only effective compound for the cyoprotection of this organism. Similar results were previously reported for tests with Chlamydomonas reinhardtii (Crutchfield et al. 1999; Scarbrough \& Wirschell 2016; Yang \& Li 2016).

Neither of the CPAs tested had direct inhibitory effects on the growth of C. chlorastera, which leads to the indication of lethal damaging occurring at some point during the freezing/thawing of samples. Indeed, Yang and $\mathrm{Li}$ (2016) described, in tests with $C$. reinhardtii, that methanol was effective in attenuating the degradation of membrane lipids during the process, results that were not replicated with DMSO. As the complexity of the organisms to be maintained in liquid nitrogen storage increases, specific tests of protocol are necessary to reach the most adequate protocol, to avoid cryo-injury and other damaging effects of this stressful process for cultures.

\section{Consequences of a cryopreserved biobank: perspectives for CCMA-UFSCar}

The necessity for the establishment of a cryopreserved biobank is linked to several practical considerations including: the reduction of costs associated with routine transfers and the space necessary for the maintenance of cultures, the reduced risks of contamination and the maintenance of genetic integrity (Brand et al. 2013). Thus, it is recommended that culture collections/ Biological Resource Centers should maintain most of their holdings in cryopreserved stocks (OECD 2007), to avoid the occurrence of genetic mutations, which will directly alter the characteristics of the cultures (Brand et al. 2013; Grout 1995). This is specifically true for strains of high commercial or scientific value, as only cryopreservation has the potential to guarantee their long term stability, including their potential to produce biotechnologically interesting products (Day 2004; Hipkin et al. 2014). CCMA-UFSCar microalgae are distributed as the starting point for research projects throughout Brazil, and much data can be found on the importance and applicability of the maintained strains. Thus, the guaranteed stability offered by cryopreservation can provide insurance for the continuity of academic activities and possible applications of microalgae-derived compounds. Furthermore, as the collection is part of a laboratory in a Federal Institution, and not individually institutionalized, the maintenance personnel are mostly undergraduate and post-graduate students, who have to work in tandem with the development of their own research projects. Thus, the reduction of the cost and effort necessary for the constant sub-culturing is essential for the possibility of expansion of the culture holdings which was a result of the FAPESP Project efforts on the study of Brazilian biodiversity. Also, for the maintenance of cryopreserved stocks in liquid nitrogen dewars, the space required is reduced, another positive point in a university laboratory.

The positive results obtained for the initial pilot study on establishment of a cryopreserved biobank for CCMA-UFSCar illustrated the feasibility of introducing these practices for microalgae culture collections in Brazil, successfully conserving the largest part of the collection stocks, which as currently small unicellular organisms. However, it must be noted that some strains of microalgae are apparently truly cryopreservation-recalcitrant due to the nature of their susceptibility to injury (Day 2004). Also, some organisms require the dedicated studies in order to obtain the highest viability rates, due to specificities in their biochemical composition and physical cell characteristics. Therefore the success observed using the protocols outlined in this study, whilst important, shows that a conventional cryopreservation protocol cannot be applied to the full range of algal taxa held in the collection and further developmental work is needed to maximize the applicability of this approach to algal curation at CCMA-UFSCar.

\section{Acknowledgements}

We thank the São Paulo Research Foundation (FAPESP) for financial support and scholarships. We are also grateful to the reviewers for comments which helped to improve the manuscript.

\section{Author Contributions}

Armando Augusto Henriques Vieira: substantial contribution in the concept and design of the study; contribution to manuscript preparation and critical revision.

John Godfrey Day: substantial contribution in the concept and design of the study; contribution to data analysis and interpretation; contribution to manuscript preparation and critical revision.

Leticia Piton Tessarolli: substantial contribution in the concept and design of the study; contribution to data collection; contribution to data analysis and interpretation; contribution to manuscript preparation and critical revision.

\section{Conflicts of interest}

The authors declares that they have no conflict of interest related to the publication of this manuscript.

\section{References}

AMARAL, R., PEREIRA, J.C., PAIS, A.A.C.C. \& SANTOS, L. 2013. Is axenicity crucial to cryopreserve microalgae? Cryobiology, 67(3), 312-320.

BRAND, J.J., ANDERSEN, R.A. \& NOBLES jr, D.R. 2013. Maintenance of microalgae in culture collections. In: Handbook of Microalgal Culture: Applied Phycology and Biotechnology, $2^{\text {nd }}$ ed, 80-89.

CRUTCHFIELD, A., DILLER, K. \& BRAND, J. 1999. Cryopreservation of Chlamydomonas reinhardtii (Chlorophyta). Eur J Phycol, 34(1), 43-52.

DAY, J.G. 2004. Cryopreservation: fundamentals, mechanisms of damage on freezing/ thawing and application in culture collections. Nova Hedwigia, 79(1-2), 191-205.

DAY, J.G. 2007. Cryopreservation of microalgae and cyanobacteria. In: Cryopreservation and freeze-drying protocols, 141-151.

DAY, J.G. \& BRAND, J.J. 2005. Cryopreservation methods for maintaining microalgal cultures. In: Algal culturing techniques, 165-187.

DAY, J.G. \& FLECK, R.A. 2015. Cryo-injury in algae and the implications this has to the conservation of micro-algae. Microalgae Biotech, 1-11.

DAY, J.G., FLECK, R.A. \& BENSON, E.E. 2000. Cryopreservation-recalcitrance in microalgae: novel approaches to identify and avoid cryo-injury. J Appl Phycol, 12(3-5), 369-377.

DAY, J.G. \& HARDING, K. 2008. Cryopreservation of algae. In: Plant Cryopreservation: A Practical Guide. Springer, p. 95-116.

DAY, J.G. \& STACEY, G.N. 2007. Cryopreservation and freeze-drying protocols. Edtion ed.: Springer ISBN 1588293777.

DE MORAES, G.P. \& VIEIRA, A.A.H. 2014. Fourier Transform Infrared with Attenuated Total Reflectance Applied to the Discrimination of Freshwater Planktonic Coccoid Green Microalgae. PloS one, 9(12), e114458.

DOEBBLER, G. 1966. Cryoprotective compounds: Review and discussion of structure and function. Cryobiology, 3(1), 2-11.

GARCIA, T.S., BOCK, C., SANT’ANNA, C.L., BAGATINI, I.L., WODNIOK, S. \& VIEIRA, A.A.H. 2017. Selenastraceae (Sphaeropleales, Chlorophyceae): rbcL, 18S rDNA and ITS-2 secondary structure enlightens traditional taxonomy, with description of two new genera, Messastrum gen. nov. and Curvastrum gen. nov. Fottea, 17(1), 1-19.

GROUT, B.W.W. 1995. Introduction to the in vitro preservation of plant cells, tissues and organs. In: Genetic preservation of plant cells in vitro. Springer, p. 1-20. 
GUILLARD, R. \& LORENZEN, C. Yellow-green algae with chlorophyllide. 1972. J Phycol, 8, 10-14.

HIPKIN, R., DAY, J.G., RAD-MENÉNDEZ, C. \& MOCK, T. 2014. The first evidence for genotypic stability in a cryopreserved transgenic diatom. J Appl Phycol, 26(1), 65-71.

HUBALEK, Z. 2003. Protectants used in the cryopreservation of microorganisms. Cryobiology, 46(3), 205-229.

LORENZ, M., FRIEDL, T. \& DAY, J.G. 2005. Perpetual maintenance of actively metabolizing microalgal cultures. In: Algal Culturing Techniques, Academic Press, New York, 145-156.

LOURENÇO, S.O. \& VIEIRA, A.A. 2004. Culture collections of microalgae in Brazil: progress and constraints. Nova Hedwigia, 79(1-2), 149-173.

MAZUR, P. 1984. Freezing of living cells: mechanisms and implications. Am J Physiol-Cell Ph, 247(3), C125-C142.

MORRIS, G.J., COULSON, G.E. \& ENGELS, M. A 1986. Cryomicroscopic Study of Cylindrocystis brebissonii De Bary and Two Species of Micrasterias Ralfs (Conjugatophyceae, Chiorophyta) during Freezing and Thawing. J Exp Bot, 37(6), 842-856.

OECD. 2007. OECD Best Practice Guidelines for Biological Resource Centres. Edtion ed. Paris: OECD Publishing. ISBN 926412876X.
SCARBROUGH, C. \& WIRSCHELL, M. 2016. Comparative analysis of cryopreservation methods in Chlamydomonas reinhardtii. Cryobiology, 73(2), 291-295.

TAYLOR, R. \& FLETCHER, R.L. 1998. Cryopreservation of eukaryotic algae-a review of methodologies. J Appl Phycol, 10(5), 481-501.

VIEIRA, H.H., BAGATINI, I.L., GUINART, C.M. \& VIEIRA, A.A.H. 2016. tufA gene as molecular marker for freshwater Chlorophyceae. Algae, 31(2), 155-165.

WENG, L., LI, W., ZUO, J. \& CHEN, C. 2011. Osmolality and unfrozen water content of aqueous solution of dimethyl sulfoxide. J Chem Eng Data, 56(7), 3175-3182.

YANG, D. \& LI, W. 2016. Methanol-Promoted Lipid Remodelling during Cooling Sustains Cryopreservation Survival of Chlamydomonas reinhardtii. PloS one, 11(1), e0146255.

YU, Z.-W. \& QUINN, P.J. 1994. Dimethyl sulphoxide: a review of its applications in cell biology. Bioscience reports, 14(6), 259-281.

Received: 11/11/2016

Revised: 14/02/2017

Accepted: 05/03/2017

Published online: 27/03/2017 